\title{
Comparison of Electroacupuncture and Moxibustion for Relieving Visceral Hypersensitivity in Rats with Constipation-Predominant Irritable Bowel Syndrome
}

\author{
Ji-Meng Zhao, ${ }^{1}$ Liu Chen, ${ }^{1}$ Ci-Li Zhou, ${ }^{2}$ Yin Shi, ${ }^{1,2}$ Yu-Wei Li, ${ }^{1}$ Hai-Xia Shang, ${ }^{1}$ Lu-Yi Wu, \\ Chun-Hui Bao, ${ }^{2}$ Chuan-Zi Dou, ${ }^{2}$ and Huan-Gan Wu ${ }^{1,2}$ \\ ${ }^{1}$ Shanghai University of Traditional Chinese Medicine, Shanghai 201203, China \\ ${ }^{2}$ Shanghai Institute of Acupuncture-Moxibustion and Meridian, Shanghai 200030, China
}

Correspondence should be addressed to Yin Shi; flysy0636@163.com and Huan-Gan Wu; wuhuangan@126.com

Received 1 April 2016; Accepted 11 August 2016

Academic Editor: Hyunsu Bae

Copyright (c) 2016 Ji-Meng Zhao et al. This is an open access article distributed under the Creative Commons Attribution License, which permits unrestricted use, distribution, and reproduction in any medium, provided the original work is properly cited.

Aim. To compare whether there is different effect between electroacupuncture (EA) and moxibustion (Mox) on visceral hypersensitivity (their analgesic effects) in constipation-predominant irritable bowel syndrome (C-IBS). Methods. EA at $1 \mathrm{~mA}$ and $3 \mathrm{~mA}$ and Mox at $43^{\circ} \mathrm{C}$ and $46^{\circ} \mathrm{C}$ were applied to the Shangjuxu (ST37, bilateral) acupoint in rats with C-IBS and normal rats. An abdominal withdrawal reflex (AWR) score was used to assess visceral hypersensitivity. Toluidine blue staining was used to assess mast cell (MC) activity in colon of rats. Immunochemistry was used to measure 5-HT and 5-HT4 receptor expression in the colon. Results. AWR scores in all EA $(1 \mathrm{~mA}$ and $3 \mathrm{~mA})$ and Mox $\left(43^{\circ} \mathrm{C}\right.$ and $\left.46^{\circ} \mathrm{C}\right)$ treatment groups after colorectal distention $(\mathrm{CRD})$ stimulation pressure of $20,40,60$, and $80 \mathrm{mmHg}$ were significantly lower than those of the model (MC) group $(P$ all $<0.01)$. The $\mathrm{MC}$ counts and degranulation rates in the colon of all EA and Mox treatment groups and the MC group were significantly higher than those of the NC group $(P$ all $<0.01)$. MC degranulation rates in the colon of all EA and Mox treatment groups were lower than those of the MC group $(P$ all $<0.05)$. 5-HT expression in colon of all EA and Mox treatment groups was significantly lower than that of the MC group $(P$ all $<0.01)$, and 5-HT4R expression in colon of both EA groups was significantly higher than that of the MC group $(P$ both $<0.01)$. Conclusion. EA and Mox treatments may both ameliorate visceral hypersensitivity at different degree in rats with C-IBS, and EA treatment was better than Mox.

\section{Introduction}

Irritable bowel syndrome (IBS) is a common functional gastrointestinal disorder featuring abdominal discomfort or pain associated with abnormal bowel movements. IBS with constipation as a chief feature accounts for $44 \%$ of IBS cases [1]. The pathology of C-IBS is complicated but current data suggest it to be mainly caused by altered gut motility and visceral hypersensitivity [2-4]. In the pathogenesis and clinical study of C-IBS, 5-HT, 5-HT4R, and MC become the focus of research in the modern medical field. 5-HT is an important neurotransmitter and paracrine signaling molecule in the gastrointestinal tract which may directly or indirectly regulate reflective gastrointestinal motor and secretory functions and modulate intestinal pain perception under certain conditions [5, 6]. 5-HT4R is an important 5 -HT receptor involved in regulating intestinal function. Activation of 5-HT4R may influence intestinal sensitivity and motility by stimulating nerve endings to release acetylcholine, or by directly targeting smooth muscle functions [7]. MCs are immune cells present in the intestinal tract that upon activation leave preformed granules to interact with local intestinal nerve fibers and mediate allergic responses through peripheral nerves that contribute to visceral hypersensitivity in IBS patients $[8,9]$. Modern studies suggest that, as a type of mechanical stimulation, acupuncture works by piercing metal needles into different acupoints by certain depths and stimulating manipulations such as lifting, thrusting, and twirling way. Moxibustion is a thermal stimulation in which burning moxa produces thermal stimulation to the human 
body. Many studies indicate that electroacupuncture (EA) and moxibustion (Mox) can regulate C-IBS. Both techniques are reported to activate receptors or other bioactive substances at acupoints and produce nerve stimulation which is transmitted through afferent nerve fibers to the CNS and then to target organs [10-13].

In this study, we aimed to analyze whether there is different effect between EA with different current intensities and Mox with different temperatures on visceral hypersensitivity (their analgesic effects) in C-IBS. We used a C-IBS rat model to examine whether electroacupuncture at different current intensities and moxibustion at different temperatures can lead to activation of mast cells and expression changes of 5-HT and 5-HT4R in colon to relieve visceral hypersensitivity or analgesic effects.

\section{Materials and Methods}

2.1. Materials. Sixty Sprague-Dawley (SD) rats (male, specific-pathogen-free, $200 \pm 10 \mathrm{~g}$ ) were supplied by Shanghai University of Traditional Chinese Medicine. Experiments were conducted strictly in accordance with the National Institute of Health Guide for the Care and Use of Laboratory Animals and the Guidelines of the International Association for the Study of Pain. All efforts were made to minimize the number of animals used and their suffering. All animal experiments in this study were performed under the guidelines approved by the Animal Ethics Committee of the Shanghai University of TCM.

2.2. C-IBS Model Establishment. An experimental rat model of C-IBS was established as previously study described [14]. Fifty adult male Sprague Dawley rats were given normal saline via intragastric administration $\left(0\right.$ to $4^{\circ} \mathrm{C}, 10 \mathrm{~mL} / \mathrm{kg}$ ) for 14 consecutive days. Ten normal control rats received no treatment. Then, all rats were housed at a constant temperature and a humidity environment with free access to food and water. On the 28th day after the end of model development, five rats were randomly chosen from the experimental group and five rats were chosen from the normal control group to confirm that the models were successfully generated by observing their feces characteristics and abdominal withdrawal reflex (AWR) scores which was assessed by colon sensitivity to colorectal distention (CRD).

2.3. Treatment. Fifty C-IBS rats were randomly assigned to five groups, as follows: (1) EA $1 \mathrm{~mA}$ group $(n=10)$ : needles (0.22 mm diameter, $13 \mathrm{~mm}$ length, Hwato, Suzhou Medical Appliance Factory, Ltd, Suzhou, China) were inserted 3$5 \mathrm{~mm}$ into the skin at the ST37 (Shangjuxu, bilateral), each acupuncture needle was connected to a HANS-100 pain relieving apparatus (Nanjing Jisheng Medical Science and Technology, Ltd., Nanjing, China) with a stimulation frequency of $2.0 \mathrm{~Hz}$ and a stimulation intensity of $1.0 \mathrm{~mA}$. (2) EA $3 \mathrm{~mA}$ group $(n=10)$ : the treatment was the same as EA $1 \mathrm{~mA}$ group but the stimulation intensity was $3 \mathrm{~mA}$. (3) Mox $43^{\circ} \mathrm{C}$ group $(n=10)$ : fine moxa made for animal experiments was ignited and placed $20 \mathrm{~mm} \pm 5 \mathrm{~mm}$ above the acupoint. A surface thermometer (Testo 905-T2, Testo, Germany) was used to confirm the temperature $\left(43 \pm 1^{\circ} \mathrm{C}\right)$. (4) Mox $46^{\circ} \mathrm{C}$ group $(n=10)$ : the treatment was the same as Mox $43^{\circ} \mathrm{C}$ group but the temperature was confirmed to be $46 \pm 1^{\circ} \mathrm{C}$. (5) MC group $(n=10)$ : no treatment was applied but they were monitored the same as the experimental treatment groups. Ten normal rats were used as NC group.

The acupoints of bilateral ST37 were selected and EA and Mox were each applied for a total of $10 \mathrm{~min}$, once daily for seven consecutive days. The ST37 acupoints of rats are located in the hind legs, about $10 \mathrm{~mm}$ below the fibula head at the lower outer side of the knee [15].

2.4. Abdominal Withdrawal Reflex (AWR) Scores before and after Treatment. After treatments, abdominal withdrawal reflex (AWR) scores were used to assess rat sensitivity to CRD using a procedure as previously study described [16]. A $2 \mathrm{~cm}$ balloon was made from a latex glove finger and attached to a $10 \mathrm{~cm}$ latex tubing that was connected to a mercury sphygmomanometer and a syringe via a three-way connector. During experiments, the balloon was coated with liquid wax and inserted slowly into the colon from the anus, about $2 \mathrm{~cm}$ deep, following physiological curvatures. When the balloon reached the descending colon, the rat was acclimated to the inserted balloon and air was injected into the balloon using a syringe at four different pressures: 20, 40, 60, and $80 \mathrm{mmHg}$. Each CRD lasted about $20 \mathrm{~s}$. Rat AWRs were recorded blindly and expressed as the threshold of sensitivity. CRD of each intensity was repeated three times and the mean score was used as the final score. AWR scores standards are as follows: 0: no behavioral response to CRD; 1 : immobility with occasional head movement; 2: mild abdominal contraction (but the abdomen did not lift from the platform); 3: a strong abdominal muscle contraction (and the abdomen lifted off the platform); 4: pelvic structures being lifted off the platform and the body arching.

2.5. Toluidine Blue Staining. Toluidine blue staining was used to stain MCs. First deparaffinization and hydration of $4 \mu \mathrm{m}$ paraffin-embedded sections were achieved by soaking xylenes I and II for $20 \mathrm{~min}$ each and anhydrous graded ethanol was applied $(90,80$, and $70 \%$ for $5 \mathrm{~min}$ each). Then, toluidine was added to the tissue sections and stained for $20 \mathrm{~min}$. Samples were washed in distilled water for $10 \mathrm{~s}$ and $0.5 \%$ acetic acid was added to differentiate color. Slides were observed under a light microscope until the cytoplasm turned purple-red. Samples were dehydrated with 95\% ethanol for $1 \mathrm{~min}$ and then with anhydrous ethanol for $1 \mathrm{~min}$ twice. Tissues were cleared twice with xylene for $20 \mathrm{~min}$ each. The appropriate amount of neutral resin was added and sections were covered to be sealed. The sample slides $(400 \mathrm{x})$ and counted MCs were observed. Cytoplasmic granules were purple-red and nuclei were blue. Smooth and intact cytoplasmic membranes with clear nuclear staining indicated stable MCs. Broken cytoplasmic membranes with purple-red granules around cells indicated degranulated MCs. MCs were counted in three nonoverlapping random views and means were obtained for total and degranulated MCs. Degranulation rates were calculated as follows: degranulation rate $(\%)=$ degranulated MC count/total MC count $\times 100 \%$. 
TABLE 1: AWR scores of rats in each group after stimulation [M (P25, P75)].

\begin{tabular}{lccccc}
\hline Group & $n$ & $20 \mathrm{mmHg}$ & $40 \mathrm{mmHg}$ & $60 \mathrm{mmHg}$ & $80 \mathrm{mmHg}$ \\
\hline Normal & 10 & $0.00(0.00-0.00)^{\mathrm{B}}$ & $1.00(0.00-1.00)^{\mathrm{B}}$ & $1.00(1.00-1.25)^{\mathrm{B}}$ & $2.00(1.75-2.00)^{\mathrm{B}}$ \\
Model & 10 & $0.75(1.00-1.00)^{\mathrm{D}}$ & $2.00(2.00-3.00)^{\mathrm{D}}$ & $3.00(2.75-3.00)^{\mathrm{D}}$ & $4.00(3.00-4.00)^{\mathrm{D}}$ \\
Mox 43 ${ }^{\circ} \mathrm{C}$ & 10 & $0.00(0.00-1.00)^{\mathrm{A}}$ & $1.00(0.00-1.00)^{\mathrm{B}}$ & $1.50(1.00-2.00)^{\mathrm{B}}$ & $2.00(2.00-3.00)^{\mathrm{B}}$ \\
Mox 46 ${ }^{\circ} \mathrm{C}$ & 10 & $0.00(0.00-1.00)^{\mathrm{A}}$ & $1.00(1.00-1.00)^{\mathrm{B}}$ & $1.50(1.00-2.00)^{\mathrm{B}}$ & $2.00(2.00-2.25)^{\mathrm{B}}$ \\
EA 1 mA & 10 & $0.00(0.00-0.25)^{\mathrm{B}}$ & $1.00(0.00-1.00)^{\mathrm{B}}$ & $2.00(1.00-2.00)^{\mathrm{B}}$ & $2.00(2.00-3.00)^{\mathrm{B}}$ \\
EA 3 mA & 10 & $0.00(0.00-1.00)^{\mathrm{A}}$ & $1.00(0.75-1.00)^{\mathrm{B}}$ & $2.00(1.00-2.00)^{\mathrm{B}}$ & $2.00(2.00-3.00)^{\mathrm{B}}$ \\
\hline${ }^{\mathrm{A}} P<0.05{ }^{\mathrm{B}} P<0.01$, versus the normal group; ${ }^{\mathrm{D}} \mathrm{P}<0.01$, versus model group.
\end{tabular}

2.6. Immunochemistry. The detection of 5-HT and 5-HT4R in the colonic tissue of C-IBS rats was performed by immunohistochemistry. Steps are as follows: The sections were immersed into $0.01 \mathrm{~mol} / \mathrm{L}$ citrate buffer liquid ( $\mathrm{pH} 6.0$ ), microwaved at $30 \%$ power for $20 \mathrm{~min}$ for thermal fixing, waited for natural cooling about $20 \mathrm{~min}$, and then exposed to $0.3 \% \mathrm{H}_{2} \mathrm{O}_{2}$ for $20 \mathrm{~min}$ at room temperature. Following a PBS wash $(3 \times 3 \mathrm{~min}), 10 \%$ normal serum blocked nonspecific binding site at room temperature for $20 \mathrm{~min}$. Dumping excess liquid, antibodies were added drop-wise (5-HT 1:100; 5HT4R 1: 80; Santa Cruz, CA, USA) at $37^{\circ} \mathrm{C}$ for $2 \mathrm{~h}$ and then washed 3 times with PBS for 3 min. Pig Anti-Goat IgG was added drop-wise $(1: 200)$ at $37^{\circ} \mathrm{C}$ for $30 \mathrm{~min}$ and then washed 3 times with PBS for $3 \mathrm{~min}$. Streptavidin-HRP was added drop-wise $(1: 200)$ at $37^{\circ} \mathrm{C}$ for $30 \mathrm{~min}$ and then washed 3 times with PBS for $3 \mathrm{~min}$. The sections were then incubated in 3,3' -diaminobenzidine (DAB) chromogenic reagent for 8$12 \mathrm{~min}$ and water-washed and then dyed with hematoxylin lining and water-washed. After drying, the sections were sealed with neutral gum for further observation under a light microscope.

2.6.1. Image Analysis. In the fixed light intensity, we used the medical image quantitative analysis system (MIQAS) and medical image quantitative analysis software to analyze and obtain the positive area ratio of the image and optical density value (Density Optical). Positive area ratio $=$ positive area/tissue section area, and the mean value of 3 different positive areas was measured in each slice.

2.7. Statistical Analysis. All statistical analyses were performed using SPSS 19.0 (SPSS Inc., Chicago, IL). AWR scores for rats are presented as interquartile ranges. Differences in means were compared by one-way ANOVA. Nonnormal data were compared using a nonparametric test. All two-sided $P$ values $<0.05$ were considered statistically significant.

\section{Results}

3.1. AWR Score Comparisons. AWR scores of all EA and Mox treatment groups were significantly lower than those of the MC group at CRD of 20,40,60, and $80 \mathrm{mmHg}(P$ all < 0.01 ). AWR scores of the NC group were not significantly different from the EA $1 \mathrm{~mA}$ and $3 \mathrm{~mA}$ groups at CRD pressure of $20,40,60$, and $80 \mathrm{mmHg}(P$ all $>0.05)$, whereas AWR scores of the Mox $43^{\circ} \mathrm{C}$ group at $80 \mathrm{mmHg}$ and the Mox $46^{\circ} \mathrm{C}$ group at $60 \mathrm{mmHg}$ were significantly different from the $\mathrm{NC}$ group $(P$ both $<0.05)$. These data suggested that EA and Mox treatments were able to decrease visceral hypersensitivity or increase the pain threshold at different degree, but EA was better than Mox treatment (Table 1).

3.2. Change of MC Activity in Colon. Compared with the NC group, the MC counts in colon were significantly increased in all EA and Mox treatment groups and MC group $(P$ all $<$ 0.01). Compared with the MC group, the MC degranulation rates in colon were significantly decreased in all EA and Mox treatment groups $(P$ all $<0.01)$. Compared with the NC group, the $\mathrm{MC}$ degranulation rates in colon were increased in all treatment groups $(P$ all $<0.05)$. There was no significant difference in MC degranulation rates in all EA and Mox treatment groups among treatments $(P$ all $>0.05)$. These data suggested that EA and Mox treatments were able to reduce the MC degranulation rates in colon (Figures 1 and 2).

3.3. 5-HT Expression in Colon. Compared with MC group, 5-HT expression in colon was significantly decreased in all EA and Mox treatments group $(P$ all $<0.01)$. Compared with NC group, 5-HT expression in colon was not different in the EA $3 \mathrm{~mA}$ group $(P>0.05)$ and was significantly increased in the EA $1 \mathrm{~mA}$, Mox $43^{\circ} \mathrm{C}$, and Mox $46^{\circ} \mathrm{C}$ group $\left(P_{\mathrm{EA} 1 \mathrm{~mA}}<\right.$ $0.05, P_{\operatorname{Mox} 43^{\circ} \mathrm{C}}<0.01$, and $\left.P_{\operatorname{Mox} 46^{\circ} \mathrm{C}}<0.01\right)$. These data suggested that EA and Mox treatments were able to reduce 5HT expression in colon at different degree, but EA $3 \mathrm{~mA}$ was better than EA $1 \mathrm{~mA}$, Mox $43^{\circ} \mathrm{C}$, and Mox $46^{\circ} \mathrm{C}$ treatments (Figures 3 and 4).

3.4. 5-HT4R Expression in Colon. Compared with MC group, 5-HT4R expression in colon was significantly decreased in both EA $1 \mathrm{~mA}$ and $3 \mathrm{~mA}$ groups ( $P$ both $<0.01$ ), but there was no difference in both Mox $43^{\circ} \mathrm{C}$ and $46^{\circ} \mathrm{C}$ groups $(P$ both $>0.05)$. 5-HT4R expression in the EA $3 \mathrm{~mA}$ group was not different from that in the NC group $(P>0.05)$. These data suggested that EA $1 \mathrm{~mA}$ and $3 \mathrm{~mA}$ treatments were able to increase 5-HT4R expression in colon, and EA $3 \mathrm{~mA}$ was better than EA $1 \mathrm{~mA}$ treatment (Figures 5 and 6).

\section{Discussion}

In recent years, with the increase of C-IBS population, the research on their pathogenesis has attracted more and more attention. Visceral hypersensitivity and abnormal intestinal 


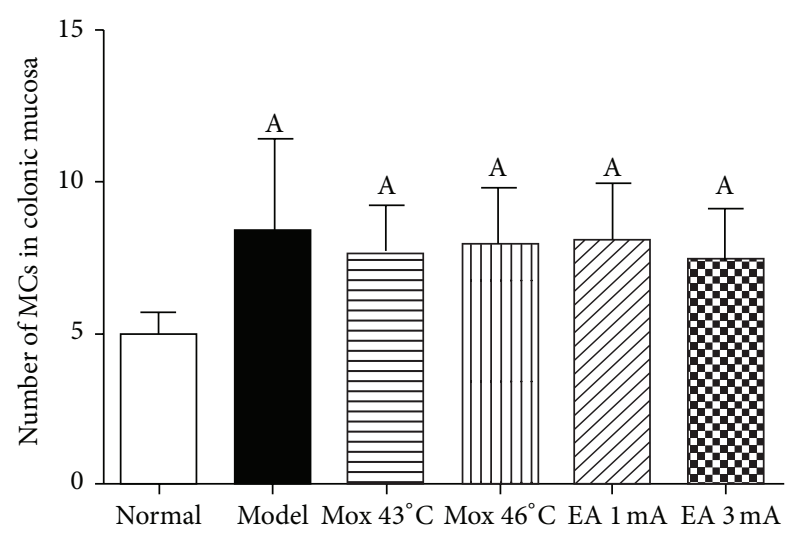

(a)

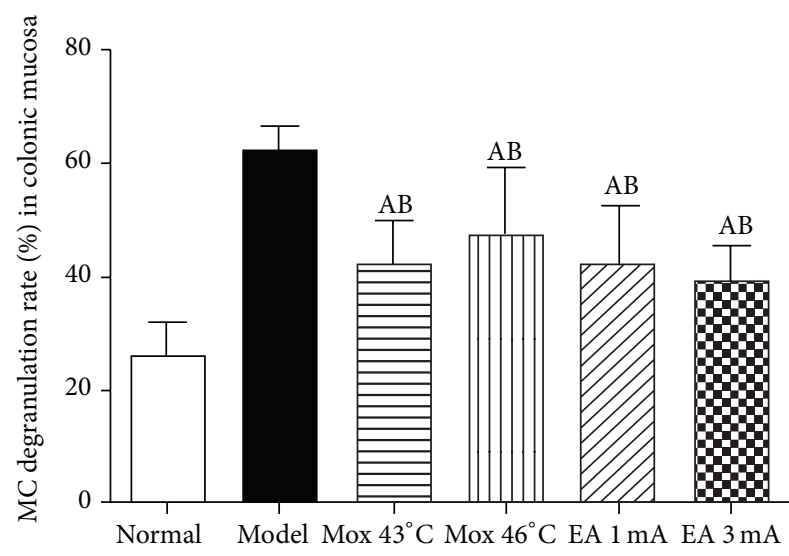

(b)

Figure 1: (a): Number of MCs in colonic mucosa in different group; (b): MC degranulation rate (\%) in colonic mucosa in different group; ${ }^{\mathrm{A}} P<0.01$, versus normal group; ${ }^{\mathrm{B}} P<0.05$, versus model group.

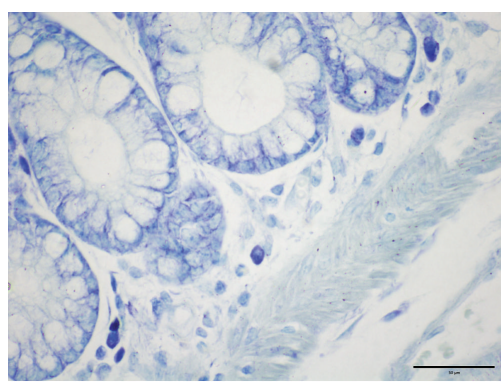

(a)

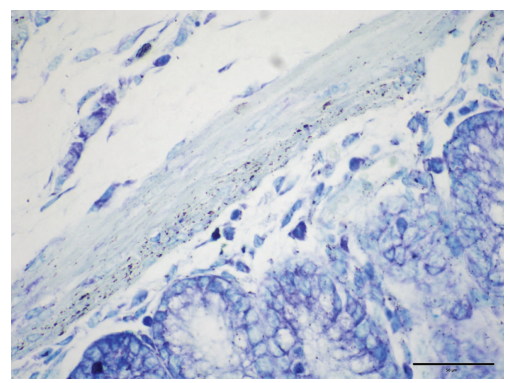

(d)

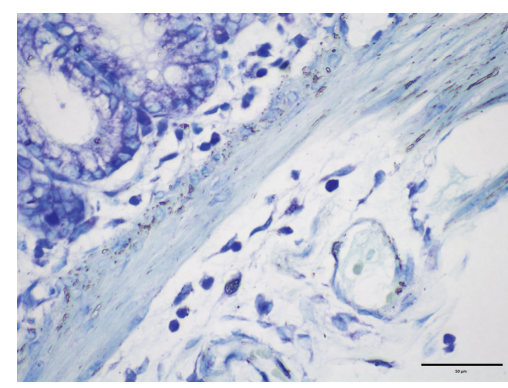

(b)

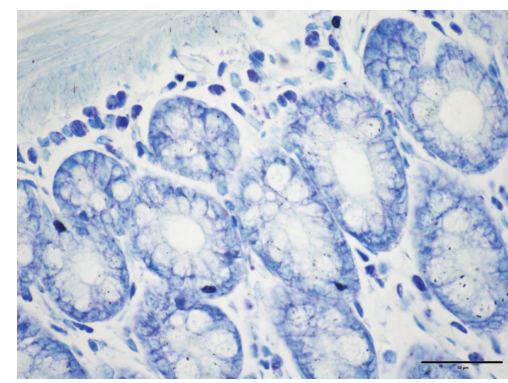

(e)

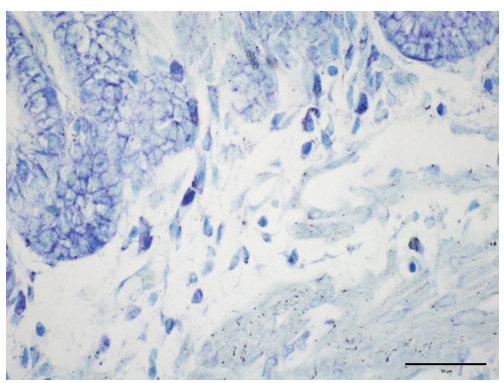

(c)

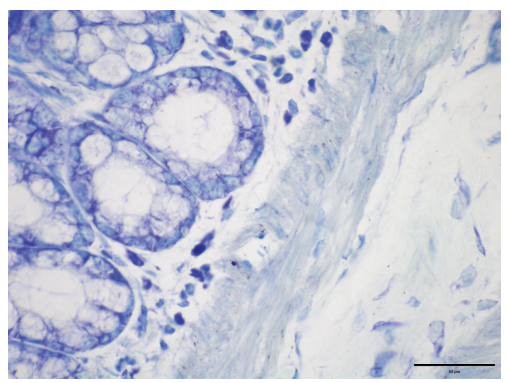

(f)

Figure 2: MC activity in colon in different group. (a): normal group; (b): model group; (c): $M o x$ 4 $3^{\circ} \mathrm{C}$ group; (d): $M o x 46^{\circ} \mathrm{C}$ group; (e): EA $1 \mathrm{~mA}$ group; (f): EA $3 \mathrm{~mA}$ group.

motility in the brain-gut axis play a pivotal role in the pathophysiology of IBS.

As an important regulatory monoamine neurotransmitter in the brain-gut axis, 5-HT is widely present in the CNS and gastrointestinal tract where $95 \%$ of $5-\mathrm{HT}$ is stored in enterochromaffin (EC) cells of the intestinal mucosa. Various stimuli such as elevated pressure in the intestinal lumen, allergic reactions, and acetylcholine can stimulate ECs to release 5-HT to signal the nervous and endocrine systems to produce visceral hypersensitivity, pain, and stool changes [17-19]. Studies suggest that, in IBS patients, an abnormal increase of 5-HT in the colon mucosa and serum is associated with visceral hypersensitivity [20-22]. We observed that 5-HT expression in MC group was significantly higher than in NC group. AWR scores of MC group were also higher than NC group, and these data suggest that overexpression of 5 - $\mathrm{HT}$ in the colon is related to visceral hypersensitivity. After treating C-IBS rats with EA at $1 \mathrm{~mA}$ and $3 \mathrm{~mA}$ or Mox at $43^{\circ} \mathrm{C}$ and $46^{\circ} \mathrm{C}$, colonic 5-HT expression decreased significantly, and AWR scores were lowered compared with MC group. In particular, the $3 \mathrm{~mA}$ current was optimal for decreasing both 5-HT expression and AWR scores, which approached that of NC group.

5-HT4R is an important 5-HT receptor that regulates gastrointestinal function [23] and 5-HT acts through 5-HT4R at the myenteric plexus to indirectly modulate gastrointestinal 


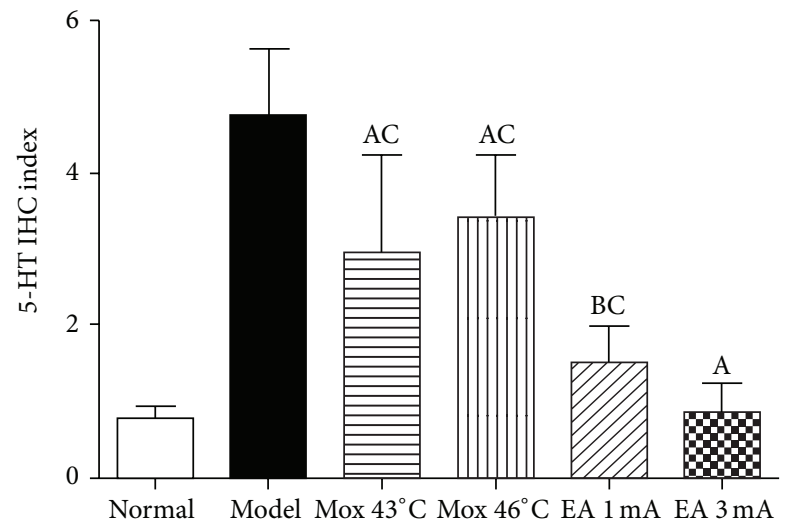

FIGURE 3: 5-HT IHC index in different group. ${ }^{\mathrm{A}} P<0.01,{ }^{\mathrm{B}} \mathrm{P}<0.05$, versus normal group; ${ }^{\mathrm{C}} \mathrm{P}<0.01$, versus model group.

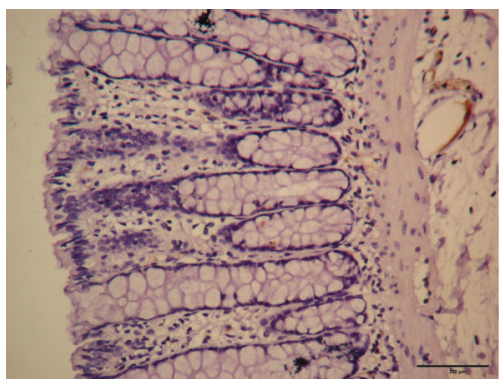

(a)

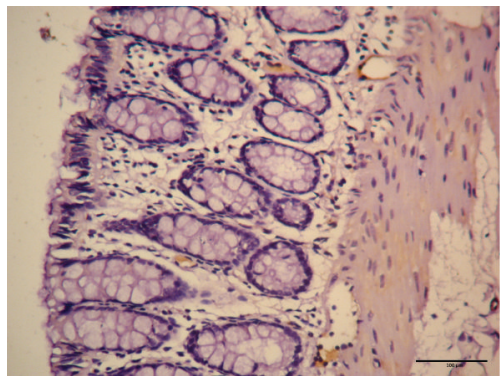

(d)

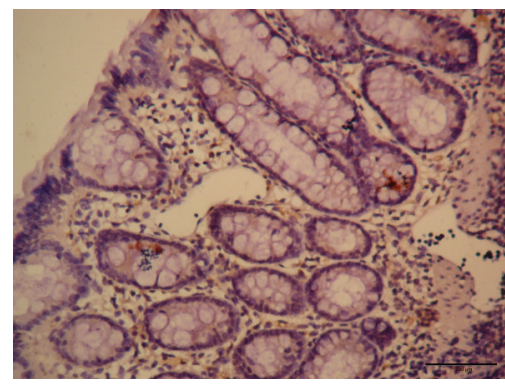

(b)

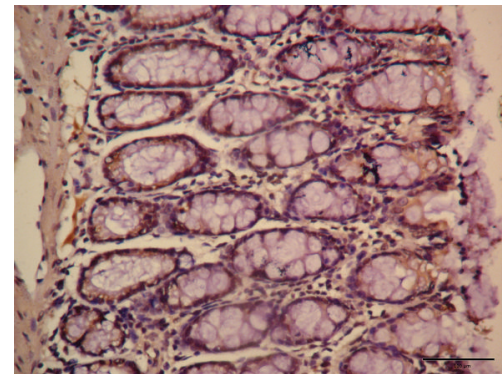

(e)

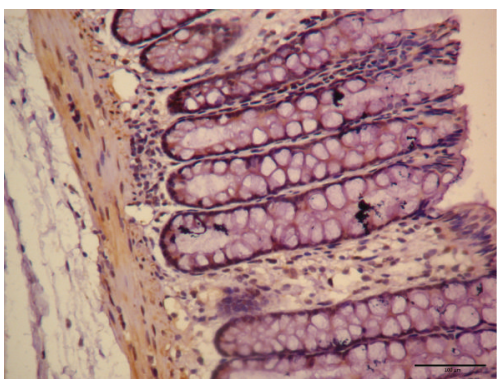

(c)

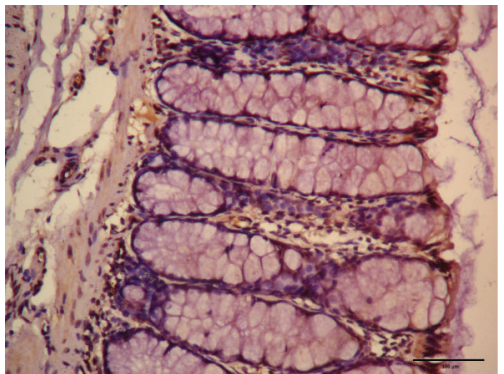

(f)

FiguRE 4: Expressions of 5-HT in colon in different group. (a): normal group; (b): model group; (c): $\operatorname{Mox} 43^{\circ} \mathrm{C}$ group; (d): Mox $46^{\circ} \mathrm{C}$ group; (e): EA $1 \mathrm{~mA}$ group; (f): EA $3 \mathrm{~mA}$ group.

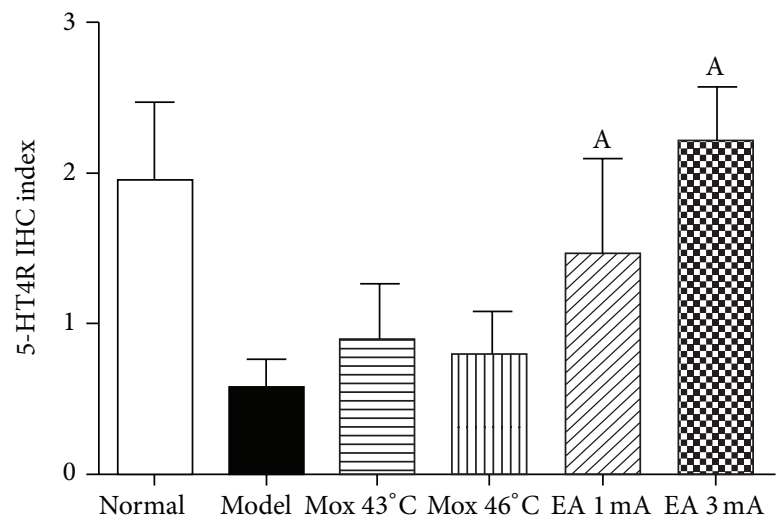

Figure 5: 5-HT4R IHC index in different group. ${ }^{\mathrm{A}} P<0.01$, versus the model group. 


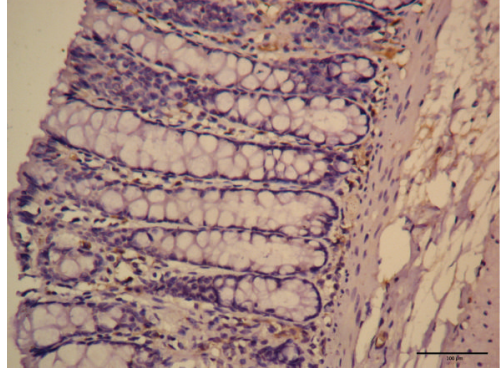

(a)

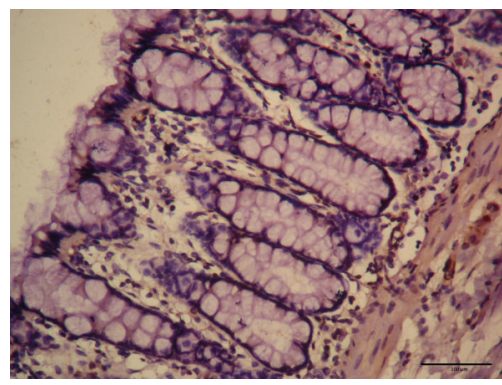

(d)

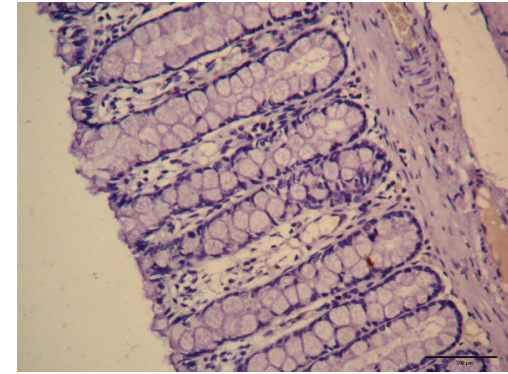

(b)

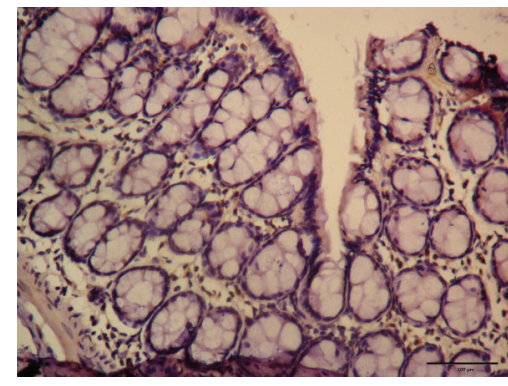

(e)

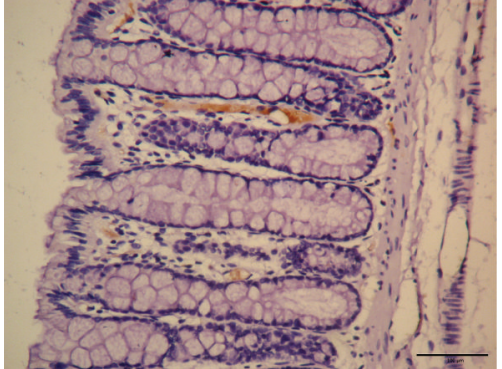

(c)

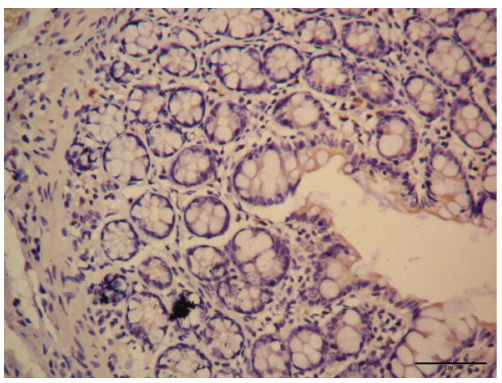

(f)

Figure 6: Expressions of 5-HT4R in colon in different group. (a): normal group; (b): model group; (c): Mox $43^{\circ} \mathrm{C}$ group; (d): Mox $46^{\circ} \mathrm{C}$ group; (e): EA $1 \mathrm{~mA}$ group; (f): EA $3 \mathrm{~mA}$ group.

motility. When activated, 5-HT4R may mediate acetylcholine (Ach) or substance P (SP) motor neurons to release neurotransmitters (SP, CGRP, VIP, and NO) that are critical for regulating gastrointestinal motility and visceral hypersensitivity [24-27]. In addition, 5-HT4R is also involved in afferent gastrointestinal sensations and 5-HT may regulate visceral pain by modulating signal transduction, activating downstream inhibitory pathways to act on presynaptic dorsal horn neurons [28]. In our experiment, 5-HT4R expression in colon was significantly lower in MC group than in NC group suggesting that abnormal expression of 5-HT4R is involved in gastrointestinal motility disorders (decreased or attenuated) and visceral hypersensitivity. After treating CIBS rats with EA at either $1 \mathrm{~mA}$ or $3 \mathrm{~mA}, 5-\mathrm{HT} 4 \mathrm{R}$ expression increased significantly and AWR scores decreased significantly. No significant difference was observed in colonic 5HT4R expression when C-IBS rats were treated with Mox at either $43^{\circ} \mathrm{C}$ or $46^{\circ} \mathrm{C}$. AWR scores of the Mox $43^{\circ} \mathrm{C}$ group at $80 \mathrm{mmHg}$ and the Mox $46^{\circ} \mathrm{C}$ group at $60 \mathrm{mmHg}$ were not significantly changed, indicating that EA was better than Mox for promoting intestinal motility and attenuating visceral hypersensitivity.

MCs are present in human and animal connective and lymphatic tissue and vessels, skin and capillaries, respiratory tract submucosa, and digestive tract [29-31]. MCs in the gastrointestinal tract can be activated by allergens, neuropeptides, and mechanical pressure. MCs, upon activation, can release these chemicals (including histamine, 5 -HT, proteoglycans, platelet activating factor, cytokines, leukotrienes, and prostaglandins), which contribute to important neurological functions such as intestinal tract smooth muscle contraction and gastrocolic reflexes, but may also induce visceral sensitivity of pain [32-37]. We observed that MCs counts in colonic tissue were higher than all EA and Mox treatment groups and $\mathrm{MC}$ group compared with NC group, suggesting that the colonic tissue of C-IBS rats has significantly more MCs during visceral hypersensitivity. MC degranulation rate in colon was higher in all EA and Mox treatment groups than in NC group, but it was significantly reduced in all treatment groups compared with MC group; this result is consistent with a previous report from our group [15]. Thus, Ea and Mox treatments can improve visceral hypersensitivity in C-IBS rats by regulating $\mathrm{MC}$ activity.

In conclusion, we observed that EA and Mox treatments may both relieve visceral hypersensitivity at different degree in rats with C-IBS and produce analgesia effect, but EA treatment was better than Mox treatment. The mechanism of these effects is likely to regulate the MC activity and the expression of 5-HT in colon of rats with C-IBS. In addition, the better effect of EA treatment on relieving visceral hypersensitivity in rats with C-IBS may be associated with regulation of 5-HT4R expression in colon.

\section{Competing Interests}

All authors approved the paper and declare that there are no conflicting financial interests for this paper.

\section{Acknowledgments}

This paper was supported by National Basic Research Program of China, 973 Program, nos. 2009CB522900 and 2015CB554501, and National Natural Science Foundation of China, no. 30973784. 


\section{References}

[1] J. Fortea and M. Prior, "Irritable bowel syndrome with constipation: a European-focused systematic literature review of disease burden," Journal of Medical Economics, vol. 16, no. 3, pp. 329341, 2013.

[2] S. Blomhoff, S. Spetalen, M. B. Jacobsen, M. Vatn, and U. F. Malt, "Intestinal reactivity to words with emotional content and brain information processing in irritable bowel syndrome," Digestive Diseases and Sciences, vol. 45, no. 6, pp. 1160-1165, 2000.

[3] Y. Sagami, T. Shoji, J. Tayama et al., "Effect of a corticotropin releasing hormone receptor antagonist on colonic sensory and motor function in patients with irritable bowel syndrome," Gut, vol. 53, pp. 958-964, 2004.

[4] P. Sinhamahapatra, S. P. Saha, A. Chowdhury, S. K. Chakrabarti, A. Ghosh, and B. Maiti, "Visceral afferent hypersensitivity in irritable bowel syndrome-evaluation by cerebral evoked potential after rectal stimulation," American Journal of Gastroenterology, vol. 96, no. 7, pp. 2150-2157, 2001.

[5] F. Şen, B. Pinarbaşi, H. Işsever, F. Akyüz, Z. Mungan, and S. Kaymakoğlu, "Postprandial platelet-poor plasma 5hydroxytryptamine concentrations during diarrhea and constipation periods of alternatingtype irritable bowel syndrome patients," The Turkish Journal of Gastroenterology, vol. 22, no. 3, pp. 270-278, 2011.

[6] J. Yang, Y. Q. Shi, and X. Y. Zhao, "SCF and 5-HT in irritable bowel syndrome patients in the intestinal mucosa of the expression and significance," Jilin Medical Journal, vol. 4, pp. 646-647, 2015.

[7] M. Nakamura, N. Ohmiya, R. Miyahara et al., "Are symptomatic changes in irritable bowel syndrome correlated with the capsule endoscopy transit time? A pilot study using the 5-HT4 receptor agonist mosapride," Hepato-Gastroenterology, vol. 58, no. 106, pp. 453-458, 2011.

[8] G. Barbara, V. Stanghellini, R. De Giorgio, and R. Corinaldesi, "Functional gastrointestinal disorders and mast cells: implications for therapy," Neurogastroenterology and Motility, vol. 18, no. 1, pp. 6-17, 2006.

[9] M. Larauche, "Novel insights in the role of peripheral corticotropin-releasing factor and mast cells in stress-induced visceral hypersensitivity," Neurogastroenterology and Motility, vol. 24, no. 3, pp. 201-205, 2012.

[10] L. Zhenzhong, Y. Xiaojun, T. Weijun et al., "Comparative effect of electroacupuncture and moxibustion on the expression of substance $\mathrm{P}$ and vasoactive intestinal peptide in patients with irritable bowel syndrome," Journal of Traditional Chinese Medicine, vol. 35, no. 4, pp. 402-410, 2015.

[11] J. Sun, X. Wu, Y. Meng et al., "Electro-acupuncture decreases 5HT, CGRP and increases NPY in the brain-gut axis in two rat models of diarrhea-predominant irritable bowel syndrome(DIBS)," BMC Complementary and Alternative Medicine, vol. 15, article 340, 2015.

[12] R. Rafiei, M. Ataie, M. A. Ramezani et al., "A new acupuncture method for management of irritable bowel syndrome: a randomized double blind clinical trial," Journal of Research in Medical Sciences, vol. 19, no. 10, pp. 913-917, 2014.

[13] B. Zhu, The Scientific Basis of Acupuncture, Qingdao Publishing House, Qingdao, China, 1998.

[14] L. H. Peng, Y. S. Yang, G. Sun, and W. F. Wang, "Constipation irritable bowel to establish a comprehensive new model of syndrome," World Journal of Gastroenterology, vol. 12, pp. 112116, 2004.
[15] Z. R. Li, Experimental Acupuncture, Chinese Medicine Press, Beijing, China, 2007.

[16] E. D. Al-Chaer, M. Kawasaki, and P. J. Pasricha, "A new model of chronic visceral hypersensitivity in adult rats induced by colon irritation during postnatal development," Gastroenterology, vol. 119, no. 5, pp. 1276-1285, 2000.

[17] Q. Yang, B. Qiu, Y. Ma, Z. J. Guo, Y. Du, and F. Z. Yun, “Constipation bowel to bowel syndrome of 5-HT in rat intestinal tissue of experimental study," Chinese Journal of Clinical Research, vol. 30, pp. 35-37, 2014.

[18] B. Niesler, J. Kapeller, C. Fell et al., "5-HTTLPR and STin2 polymorphisms in the serotonin transporter gene and irritable bowel syndrome: effect of bowel habit and sex," European Journal of Gastroenterology and Hepatology, vol. 22, no. 7, pp. 856-861, 2010.

[19] H.-L. Shi, C.-H. Liu, L.-L. Ding et al., "Alterations in serotonin, transient receptor potential channels and protease-activated receptors in rats with irritable bowel syndrome attenuated by Shugan decoction," World Journal of Gastroenterology, vol. 21, no. 16, pp. 4852-4863, 2015.

[20] Y. P. Zhao, M. P. Su, F. Y. Wang et al., "Effect of Changan Decoction No.1 on irritable 5-HT signaling system in visceral hypersensitivity rats and hippocampal BDNF mRNA expression of bowel syndrome," Chinese Journal of Integrative Medicine, vol. 10, pp. 1228-1235, 2015.

[21] M. Camilleri, "New receptor targets for medical therapy in irritable bowel syndrome," Alimentary Pharmacology \& Therapeutics, vol. 31, no. 1, pp. 35-46, 2010.

[22] M. T. Liu, Y. H. Kuan, J. Wang, R. Hen, and M. D. Gershon, "5-HT4 receptor-mediated neuropro-tection and neurogenesis in the enteric nervous system of adult mice," The Journal of Neuroscience, vol. 29, no. 31, pp. 9683-9699, 2009.

[23] C. Yan, L. Xin-Guang, W. Hua-Hong, L. Jun-Xia, and L. YiXuan, "Effect of the 5-HT4 receptor and serotonin transporter on visceral hypersensitivity in rats," Brazilian Journal of Medical and Biological Research, vol. 45, no. 10, pp. 948-954, 2012.

[24] A. Moskwa and P. Boznańska, "Role of serotonin in the pathophysiology of the irritable bowel syndrome," Wiadomości Lekarskie, vol. 60, no. 7-8, pp. 371-376, 2007.

[25] R. Mader, T. Kocher, J. Haier, G. Wieczorek, H.-J. Pfannkuche, and M. Ito, "Investigation of serotonin type 4 receptor expression in human and non-human primate gastrointestinal samples," European Journal of Gastroenterology and Hepatology, vol. 18, no. 9, pp. 945-950, 2006.

[26] Y. Q. Li, Y. S. Yang, and J. Chen, Irritable Bowel Syndrome, Chinese Medicine Science and Technology Press, Beijing, China, 2005.

[27] M. D. Crowell, "Role of serotonin in the pathophysiology of the irritable bowel syndrome," British Journal of Pharmacology, vol. 141, no. 8, pp. 1285-1293, 2004.

[28] L. A. Doyle, G. J. Sepehr, M. J. Hamilton, C. Akin, M. C. Castells, and J. L. Hornick, "A clinicopathologic study of 24 cases of systemic mastocytosis involving the gastrointestinal tract and assessment of mucosal mast cell density in irritable bowel syndrome and asymptomatic patients," American Journal of Surgical Pathology, vol. 38, no. 6, pp. 832-843, 2014.

[29] C.-J. Zhong, C.-Q. Yang, L.-P. Duan, S.-P. Zhou, and K. Zhang, "Reconstitution of mast cell population in gastrointestinal tract by bone marrow transplantation in mast cell deficient rats," National Medical Journal of China, vol. 93, no. 38, pp. 30683073, 2013. 
[30] X.-P. Ma, J. Hong, C.-P. An et al., "Acupuncture-moxibustion in treating irritable bowel syndrome: how does it work?" World Journal of Gastroenterology, vol. 20, no. 20, pp. 6044-6054, 2014.

[31] K. Cheng, X.-Y. Shen, G.-H. Ding, and F. Wu, "Relationship between laser acupuncture analgesia and the function of mast cells," Chinese Acupuncture \& Moxibustion, vol. 29, no. 6, pp. 478-483, 2009.

[32] X. M. Yang, C. Z. Liu, G. G. Shi, Y. X. Ma, S. Z. Gao, and X. Y. Wang, "Effect of umbilical therapy on irritable bowel syndrome of spleen deficiency type of serum ghrelin level of patients," China Journal of Traditional Chinese Medicine and Pharmacy, vol. 26, pp. 2266-2271, 2011.

[33] B. Chen, M. Y. Li, Y. Guo, X. Zhao, and Y. Y. Liu, "Discussion on the construction of acupuncture effect to start a small network of mast cell-derived exosomes," Acupuncture Research, vol. 40, pp. 82-85, 2015.

[34] T. K. Klooker, B. Braak, K. E. Koopman et al., “The mast cell stabiliser ketotifen decreases visceral hypersensitivity and improves intestinal symptoms in patients with irritable bowel syndrome," Gut, vol. 59, no. 9, pp. 1213-1221, 2010.

[35] D. M. McKay and M. H. Perdue, "Intestinal epithelial function: the case for immunophysiological regulation-cells and mediators (first of two parts)," Digestive Diseases and Sciences, vol. 38, no. 8, pp. 1377-1387, 1993.

[36] L. H. Wang, X. C. Fang, and G. Z. Pan, "Irritable bowel syndrome patients associated with intestinal mucosal mast cells and nerve fibers," Chinese Journal of Digestion, vol. 23, pp. 332335, 2003.

[37] H.-G. Wu, B. Jiang, E.-H. Zhou et al., "Regulatory mechanism of electroacupuncture in irritable bowel syndrome: preventing MC activation and decreasing SP VIP secretion," Digestive Diseases and Sciences, vol. 53, no. 6, pp. 1644-1651, 2008. 


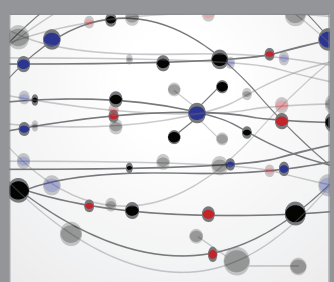

The Scientific World Journal
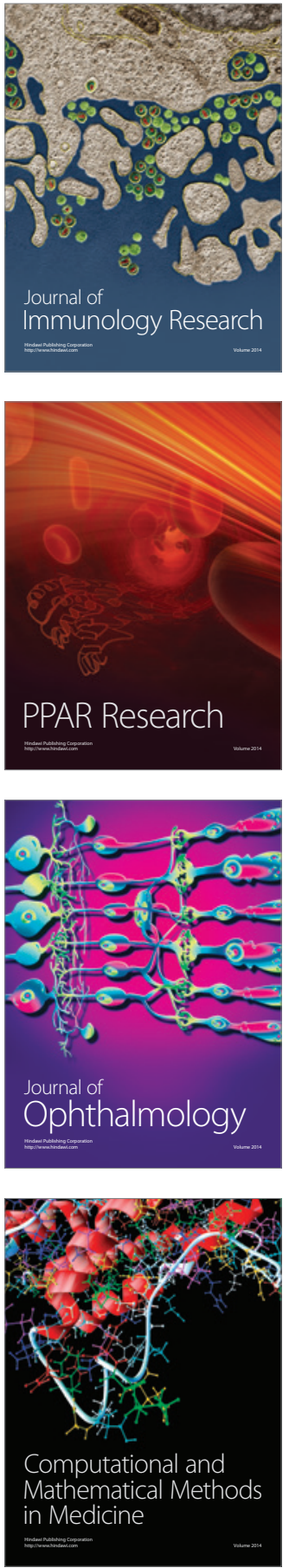

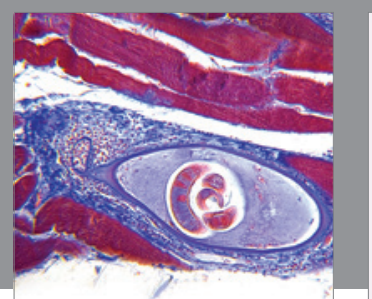

Gastroenterology Research and Practice

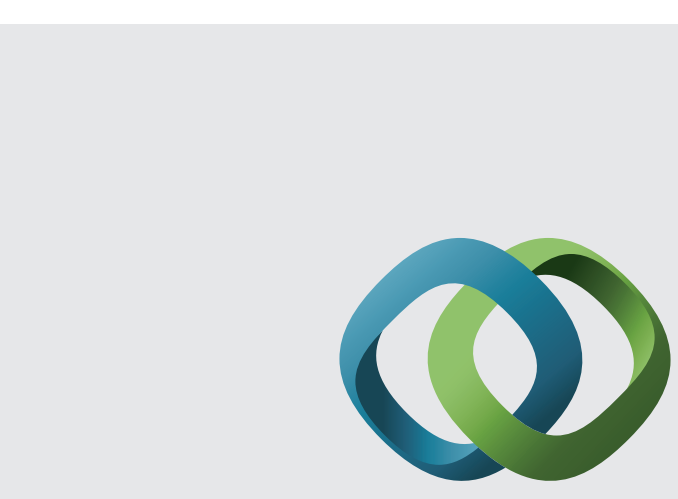

\section{Hindawi}

Submit your manuscripts at

http://www.hindawi.com
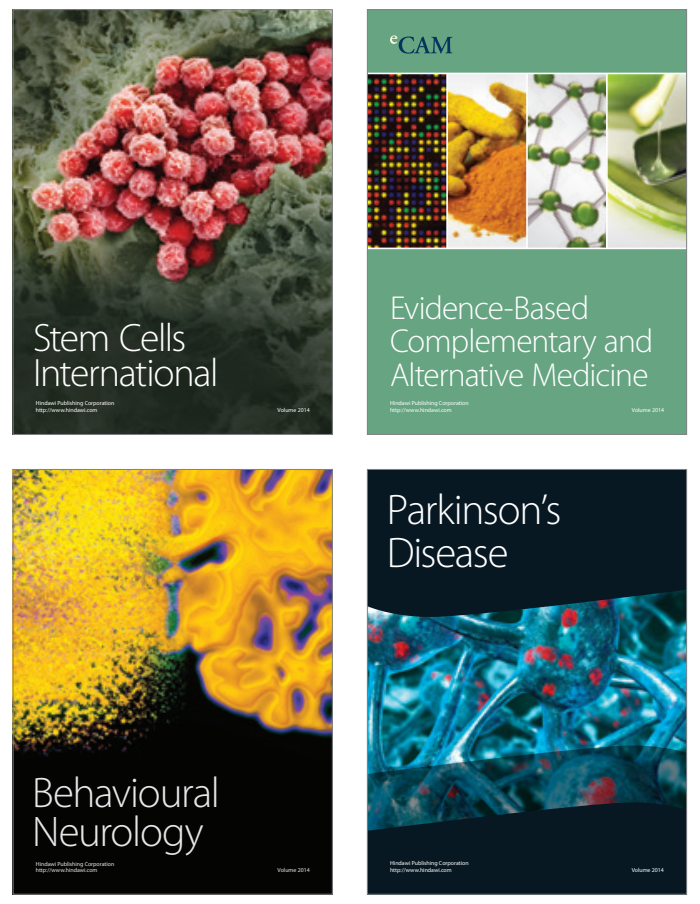
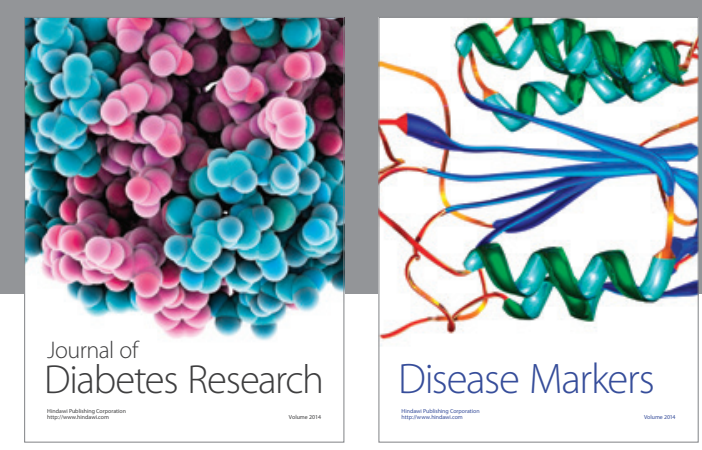

Disease Markers
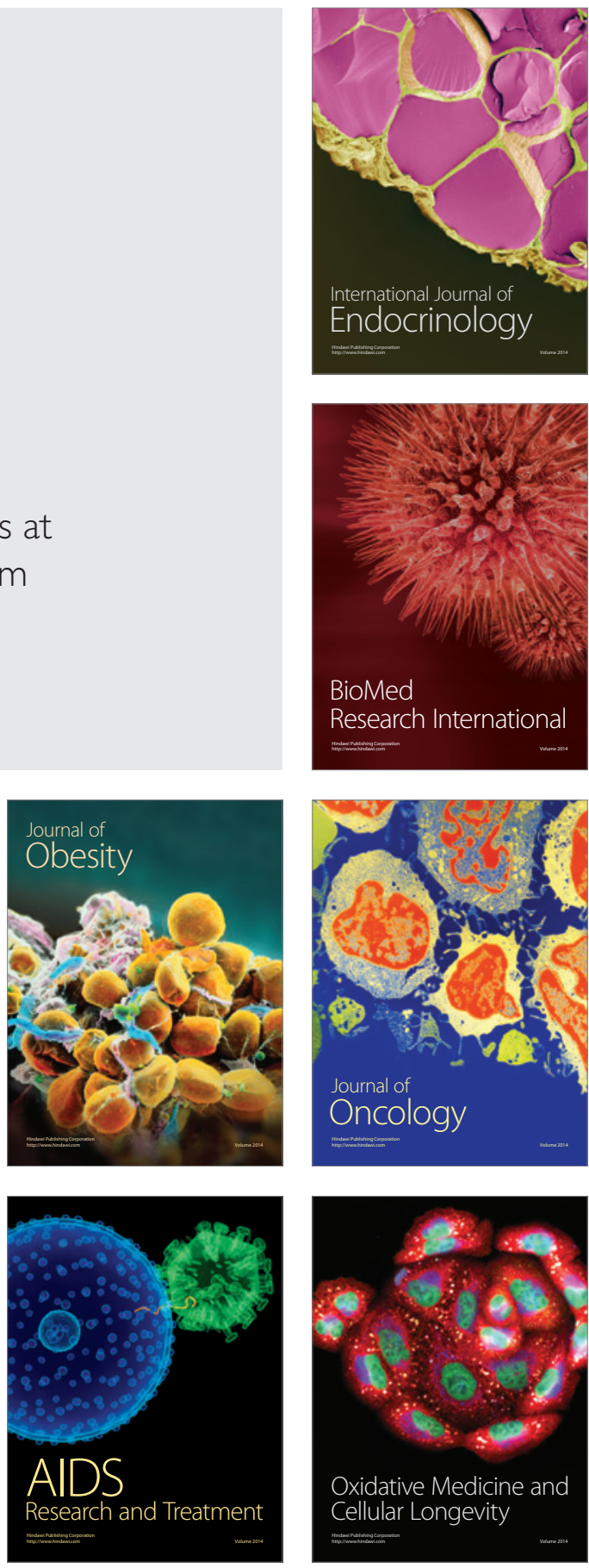